\title{
Sase Oreport \\ Spontaneous Expulsion of a Biliary Stent via the abdominal wall: A rare complication: Case Report
}

\author{
Gamal E H El Shallaly¹, El tayeb A Ali² Isam A Abdaljaleel ${ }^{3}$, Mohammed N Adam².
}

\begin{abstract}
We report a rare complication of a biliary stent inserted via endoscopic retrograde cholangio-pancreatography (ERCP) for benign biliary disease in a 60 years-old female presented with abdominal pain and a tender left iliac fossa (LIF) mass. She had change of the colour of the skin over the hypogastric region.

Crepitus was felt in the subcutaneous tissue. Surgical drainage of the abscess was undertaken. A black, $14-\mathrm{cm}$ biliary stent was found in the centre of the necrotic tissue. The patient, thereafter, made an uneventful recovery and the LIF mass disappeared. The wound was closed with secondary sutures about three weeks later, and complete healing was achieved thereafter. Here we discuss this rare complication.
\end{abstract}

\section{Keywords}

Biliary stent migration, colonic perforation, abdominal mass, large bowel obstruction, abdominal wall abscess, ERCP complication.

\section{Case Report}

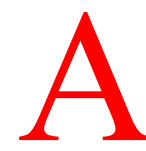

60-years old female presented with colicky lower abdominal pain and a swelling in the left iliac fossa (LIF). She had neither vomiting nor constipation. She gave history of jaundice and some endoscopic procedure abroad two years prior to her presentation. On clinical examination, she looked ill, febrile, with tachycardia, but normal blood pressure. Abdominal examination revealed a tender mass, about $5 \times 7 \mathrm{~cm}$ in the LIF. Investigations revealed high total white cell count with neutrophilia. Ultrasound confirmed the position and the dimensions of the mass.

\footnotetext{
1, 2 Consultant Surgeons. 3. Registrar in surgery,

4. House officer Al Zaem AlAzhari University Unit, Khartoum North Teaching Hospital, Sudan Correspondence to Mr. Gamal E H El Shallaly Email: gamalshallaly@hotmail.com
}

Fine needle aspiration cytology showed inflammatory cells. The patient was diagnosed as a case of inflammatory abdominal mass, and intravenous (IV) antibiotics were initiated. Two days later, the patient became toxic. Abdominal examination revealed an abscess in the anterior abdominal wall with black discolouration and ulceration of the skin below the umbilicus (Figure 1). There was crepitus on palpation of that area. The patient had incision and drainage of the abscess under general anaesthesia. The abscess cavity contained pus, air bubbles, and necrotic tissue. In the centre of the abscess was a black slightly curved biliary stent about $14 \mathrm{~cm}$ long (Figure 2).

She made an uneventful recovery. The wound was closed with secondary sutures three weeks later. Complete healing was achieved thereafter. 


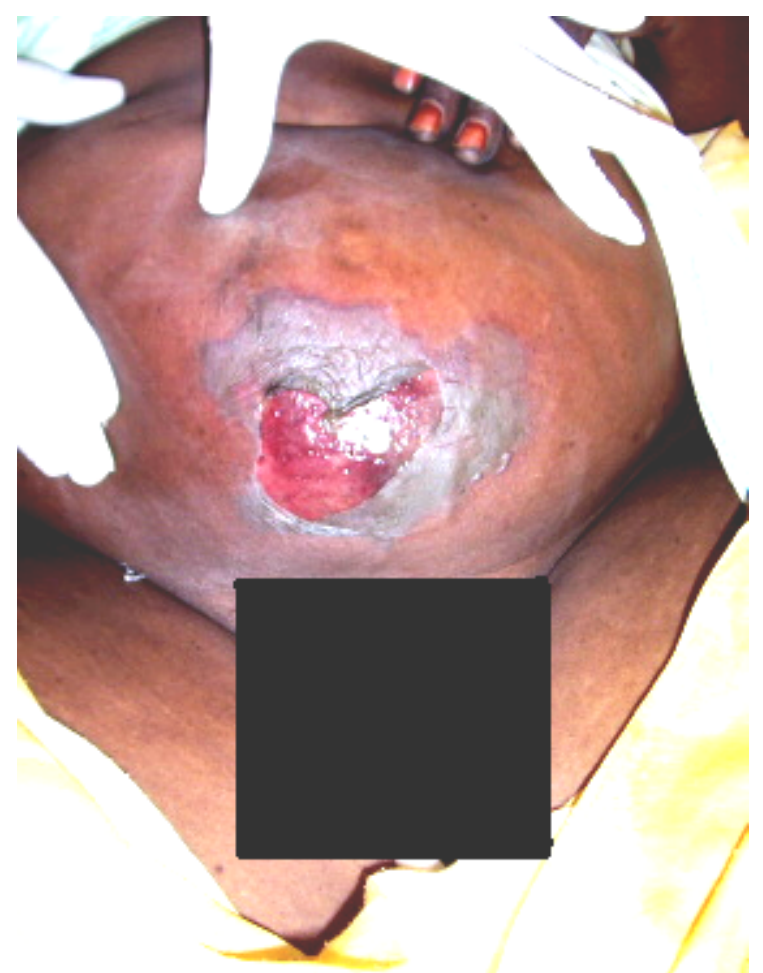

Figure1. Anterior abdominal wall Abscess

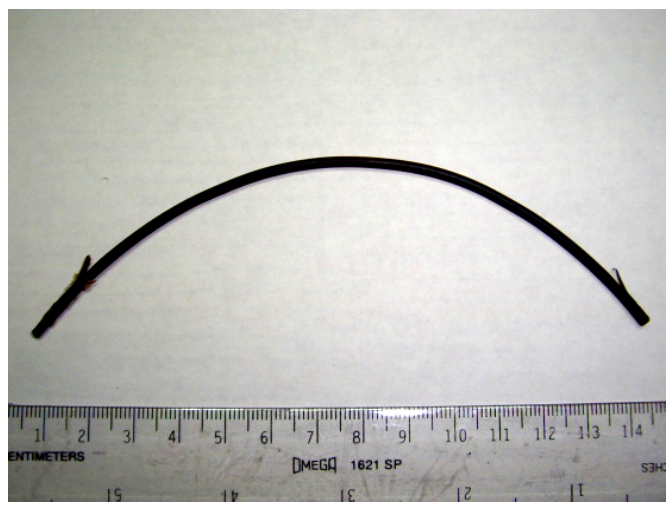

2. The biliary stent found in the abscess cavity

\section{Discussion}

Biliary stenting is an important form of management for several benign and malignant biliary obstructions. There have been reports on biliary stent complications, particularly migration, since the 1990s. Biliary and pancreatic stents may migrate either proximally (into the duct) or distally (out of the duct). However, the frequency and potential risk factors for this migration remain largely unknown. In one of the earliest reports (1992), Johanson et al demonstrated biliary stent migration rates between $4.9 \%$ and $5.9 \%$ over a period of four and a half years ${ }^{1}$. They found that, the only risk factor associated with distal migration was papillary stenosis. Strictures, larger diameter and shorter stents were associated with proximal migration. Sphincterotomy and endoscopic retrieval of proximally migrated stents were previously described $^{2,3}$. Distal migration can cause perforation of the bowel with potentially lifethreatening complications. Any part of the bowel from the duodenum to the sigmoid colon is at risk of perforation ${ }^{4-13}$.

The clinical presentations of such patients may vary from mild abdominal discomfort to acute abdomen, overt septicaemia and septic shock. Our patient presented with colicky abdominal pain in the hypogastric area not associated with vomiting or constipation. She was found to have a mass in the left iliac fossa. Although the patient had an ultrasound scan, a computed tomography (CT) scan would have been more informative. Two days after admission, the patient developed a frank abscess of the abdominal wall that pointed at the suprapubic area. At this stage conservative treatment was abandoned and surgical treatment was undertaken. In contrast to proximal migration of biliary stents, which can be treated endoscopically with $90 \%$ or more success rate, treatment of distally migrated stents with perforation eventually required definitive surgical intervention in all reports. The LIF mass disappeared after drainage of the abscess. No further discharge was noted which may indicate closure of the migration tract. In retrospect, that mass could have well been a paracolic abscess that was formed following colonic perforation by the stent. The retrieval of the stent may be associated with some risk factors for such complication $^{\mathbf{1 , 6}}$, however, further studies are needed to clarify this. Furthermore, the role of stenting the CBD for benign conditions should be reviewed. It is probably wise to attempt definitive treatment after stent insertion as soon as the patient condition permits, and not to leave it in situ for several months. 


\section{Conclusion}

Here we describe a case of spontaneous expulsion of a distally migrated biliary stent with an abdominal wall abscess formation. Bowel perforation as a complication of biliary stent placement is rare yet it is life threatening. Surgeons must have high index of suspicion, as early surgical treatment could be life saving.

\section{References}

1. Johanson JF, Schmalz MJ, Geenen JE. Incidence and risk factors for biliary and pancreatic stent migration. Gastrointest Endosc. 1992; 38(3): 341-6.

2. Tranasky PR, Cotton PB, Baillie J, et al. Proximal migration of biliary stents: attempted endoscopic retrieval in forty-one patients. Gastrointest Endosc. 1995: 42(6): 513-20.

3. Chaurasia OP, Raus EA, Fockens P, et al. Endoscopic techniques for retrieval of proximally migrated biliary stents: The Amsterdam experience. Gastrointest Endosc. 1999; 50 (6): 780-5.

4. Bui BT, Oliva VL, Ghattas G, et al. Percutaneous removal of a biliary stent after acute spontaneous duodenal perforation. Cardiovasc Intervent Radiol. 1995; 18(3): 200-2.
5. Schaafsma RJ, Spoelstra P, Pakan J, et al. Sigmoid perforation: a rare complication of a migrated biliary endoprosthesis. Endoscopy 1996; 28 (5): 469-70.

6. Baty V, Denis B, Bigard MA, et al. Sigmoid Diverticular perforation relating to the migration of a polyethylene endoprosthesis. Endoscopy. 1996; 28(9): 781.

7. Lenzo NP, Garas G. Biliary stent migration with colonic Diverticular perforation. Gastrointest Endosc. 1998; 47(6): 543-4.

8. Mastorakos DP, Milman PJ, Cohen R, et al. An unusual complication of a biliary stent-small bowel perforation of an incarcerated hernia sac. Am J Gastroenterol. 1998; 93(12): 2533-5.

9. Mofidi R, Ahmed K, Mofidi A, et al. Perforation of ileum: an unusual complication of distal biliary stent migration. Endoscopy. 2000; 32(11): 567.

10. Mistry BM, Memon MA, Silverman R, et al. Small bowel perforation from a migrated biliary stent. Surg Endosc. 2001; 15(9): 1043.

11. Elliott M, Boland S. Sigmoid colon perforation following a migrated biliary stent. ANZ J Surg. 2003; 73(8): 669-70.

12. Miller G, Yim D, Macari M, et al. Retroperitoneal perforation of the duodenum from biliary stent erosion. Curr Surg. 2005; 62(5): 512-5.

13. Lanteri R, Naso P, Rapisarda C, et al. Jejunal perforation for biliary stent dislocation. Am J Gastroenterol. 2006; 101(4): 908-9. 